\title{
The Relationship of Accountable Governance and Constitutional Implementation, with Reference to Africa
}

\author{
Peter Burnell \\ Department of Politics and International Studies \\ University of Warwick, Coventry, CV4 7AL, England \\ Tel : 44-24-7652-3304 E-mail: peter.burnell@warwick.ac.uk
}

A previous and longer version of this article was presented in the Department of Public Law, University of Cape Town, South Africa in April 2008 under the British Council DELPHE (Development Partnerships in Higher Education) project ZA204, 'Implementing constitutional choices: enhancing accountable government on the African continent'.

\begin{abstract}
This article offers a framework for analysing the interrelationships between democratic accountability and constitutional implementation with specific reference to sub-Saharan Africa. It opens by noting the subject's importance and the contested meaning of key terms, before proceeding to elaborate the significance that constitutional implementation and accountability have for one another. The main purpose is to suggest an agenda lying at the interface between constitutional law and politics that is worthy of further research. The article argues there is considerable scope for analysts of law and politics to collaborate for the purpose of shedding light on many questions that cut across issues of both democratic accountability and constitutional implementation in Africa.
\end{abstract}

Keywords: Accountability, Constitutional implementation, Africa

\section{Introduction}

The most recent 'wave' of democratisation around the world, Africa in particular has seen a flurry of new constitution-making and constitutional revision. In some places this has been greeted as a second liberation or second coming of independence. In a parallel trend ideas of governance and the importance of 'good' governance have been in the forefront of debates about development, with the African continent again featuring prominently. Accountability is central to the theory and practice of both democracy and better governance. In Africa the importance of accountable governance to achieving economic and social development, lasting peace and political stability as well as democracy is widely assumed to be virtually axiomatic.

Accountability has been called the defining feature of modern liberal democracy: 'scholars now tend to perceive public accountability as a key attribute of democracy and democratic quality, as well as an ingredient of democracy's long-term sustainability' (Schedler 1999a: 2). Accountability makes the abuse of political power less likely, while at the same time helping to empower governments to serve the ends that democratically elected governments are legitimately asked to pursue. In 2005 the Economic Commission for Africa acknowledged in its African Governance Report (2005:116) that in the past constitutional mechanisms to contain executive dominance 'were systematically weakened, revised, suspended or replaced with ones that had a concentration of power in the executive branch'. Now, strengthened accountability arrangements including some brand new institutions are in place in many African countries. Alongside the parliaments other bodies such as Human Rights Commissions, Anti-Corruption Commissions, Public Audit Offices, National Prosecuting Authorities and of course the courts - constitutional courts included - now have more prominence compared to earlier constitutional arrangements.

However, although the idea of accountability is not new to politics there is confusion about its meaning and practice. Furthermore, the relationship of accountability to constitutionalism, constitution-building and more specifically constitutional implementation is barely addressed: the connections are rarely spelled out. For example, does the way in which constitutional choices were originally made and the reasons for those choices have an important bearing on the state of accountability later? Are some constitutional choices and institutional mechanisms more likely to secure accountable government than others? Ideas of constitution building and constitutional implementation may not be easy to separate, but does a country's experience of accountability play clearly into theories of constitutional failure and success? Before these and related questions can be addressed the analytical terrain must be surveyed first. Only then is 
it realistic to set about collecting comprehensive data about the actual performance of accountability mechanisms and connecting the evidence to constitutional implementation, in Africa's constitutional democracies. The paper surveys the terrain; the intention is that readers from law and from politics are both exposed to propositions that they find new.

\section{Ideas of accountability}

Legal, political, administrative, financial, managerial, parliamentary, moral, market, societal and, even, celestial or heavenly are just some of the prefixes that have been attached to the word accountability. In politics accountability has been called 'perhaps, the most vexing problem within contemporary democracies' (Moncrieffe 2001: 26). One of the reasons is confusion over the term itself, an aspect that Schedler (1999b: 14) captures well when he says accountability 'represents an underexplored concept whose meaning remains evasive, whose boundaries are fuzzy, and whose internal structure is confusing'.

In fact there are several interlocking debates over what accountability means and how it works in the domestic context and even that context does not describe the full reality facing many African governments that have to account also to external bodies, such as foreign aid donors, as well as the legal constraints provided by international law. In a globalising world the phenomenon of external accountability is becoming increasing important. Domestic accountability however is essential to democratic accountability. But curiously, the question of what delineates democratic accountability from the larger field of domestic accountability is rarely posed. Rakner and Gloppen (2003: 79) say democratic accountability is a special case where the "principal is "the people" and the parties owing accountability are those entrusted with political power'. A tighter specification would say something more about how the people are to function as an instrument of accountability. For example democratic accountability can be said to refer in the first instance to making government accountable to society through a democratically elected body that is representative of the people and that itself endorses democratic norms and values, or to the assigned agents of such a body, operating within the framework of the rule of law. Terms of reference like these would exclude mobocracy and show trials, among other things.

Clearly, accountability requirements may be found to apply in the relationships between different institutions and also in the relationships that exist within a single organisation. There may be a lengthy chain of principal-agent connections or nested accountability relationships coexisting alongside one another: junior officials accountable to their line managers; the civil service heads of departments accountable to their political masters; the government accountable to parliament; parliament accountable to the people. But while general questions asking who is accountable to whom and for what look straightforward enough, discourse becomes more convoluted once the relationships of such issues as enforcement, responsibility, institutional typologies, and sanctions to notions of accountability are brought into closer focus.

\subsection{Answerability and enforceability}

A commonly made distinction is between answerability and enforceability (also 'correction' or redress). On the answerability side a distinction is sometimes made between the obligation to provide information about activities (transparency) and a requirement to give reasons that should be offered as justifications for the conduct. On the enforcement side, the sanctions or threatened penalties vary greatly, from criminal charges and dismissal from office to reprimand, public embarrassment or damage to reputation. An important difference lies in the asymmetry between liability to sanction for legal misdemeanours and the enforcement of political accountability. Where the law has been complied with in full there is no case for legal sanctions. But with political accountability an agent may do what was demanded and yet still could be legitimately brought down; conversely political agents may be able to escape penalties even though their performance is poor. The predictability that sanctions will be imposed counts in determining how agents choose to act. But while in many cases the form or mode of sanction is particular to the type of accountability relationship, the more general question of which sanctions are the most effective and in what circumstances can only be established empirically.

\subsection{Ex ante and ex post}

A further common distinction is between ex ante (also 'prospective') accountability and ex post (retrospective) accountability. The former is close to the idea of responsiveness. For instance society expects government to do what society wants government to do. This is different from the ex post idea of critically examining the government's performance after the event and, where relevant sanctioning an abuse of power, maladministration or some other failing. In order to be responsive an agent must have its responsibilities clearly defined. Accountability rules aim to ensure that agents take their responsibilities seriously and act on them in a way that the principals find acceptable: 'The requirement that agents be accountable to their principal for the way they act on their responsibilities by exercising authority and carrying out their duties indicates the interrelationship of accountability and responsibility' (Dunn (1999: 300). However not every relationship of accountability hinges on a direct relationship between an agent and the principal that authorised or created that agent (Mainwaring 2003: 14-16). Accountability can mean answerability even in circumstances where the body that feels entitled to receive answers may not itself have the power to invoke 
immediate dismissal.

Within the field of oversight of the executive a similar distinction is made between ex ante and ex post scrutiny. The former examines the government's proposals and the latter looks at implementation and outturns. The precise mechanism for oversight can take different forms. Hence there is a useful distinction derived from US experience between so called 'police patrol' mechanisms (the routine scrutiny of executive action by legislative committees, for example) and the 'fire alarm' interventions that such institutions as an auditor-general or an Ombudsman make, perhaps only after suspicions about executive conduct have already been aroused. A fundamental difference throughout is between arrangements designed to check up on lawfulness and those whose remit is to examine performance. The potential for conflict between these is obvious, namely unlawful actions that deliver real benefits, and lawful conduct that leads to mediocre performance.

Where there are multi-linked chains of accountability operating at different levels and cutting across inter- as well as intra-institutional relations, the interactions and interdependencies that prevail among the various accountabilities and the potential for tension to arise between the different agencies offers intriguing scope for detailed investigation. A plausible hypothesis is that accountability relationships perform most effectively when they benefit from mutual support and reinforcement. Conversely they may be weakest when they work in isolation. Constructive disagreements could be optimal, but passing judgment on which disagreements are constructive may be problematic. These too are matters for detailed empirical investigation.

\subsection{Institutional distinctions}

Significant possibilities for empirical research in Africa are certainly present in regard to the relations between the institutions of what O'Donnell (1998) called vertical and horizontal accountability - a distinction that is now widely recognised in the study of democratisation but which carries a different meaning from the way 'horizontality' is understood by legal scholars. (There, horizontality refers to claims about rights in relations among non-state actors, in other words private relationships, as distinct from claims against the state). In O'Donnell's framework the electoral sanction is the main instrument of vertical accountability; the judiciary is a prime example of horizontal accountability. A major illustration of the way different instruments might work together combines legislative scrutiny of the public finances and investigations conducted by the national audit office: each is dependent on the other if they are to have a good chance of being fully effective.

However, the grounds for an alternative distinction, between electoral accountability and intrastate accountability (Mainwaring 2003: 18-19) are strong. It highlights the difference over to whom or to what account must be rendered (citizens, and voters in particular, versus state organs) without conveying any misleading notions about hierarchy or independence among the different institutions. Thus Mainwaring's (2003: 20) distinction between three types of intrastate accountability is extremely helpful: (i) principal-agent relationships, where the principal has control over the agent; (ii) situations where one actor does not create or control another but does have sanctioning power towards it; (iii) oversight, which is where no direct sanctioning power exists, but where the overseeing body may refer complaints to yet another body that does have such power. For example a legislative scrutiny committee may be authorised to pass its findings to the Public Prosecutor. And yet even oversight institutions might have the capability to inflict informal sanctions directly (for example, embarrassment) or to invoke sanctions more indirectly, such as when their findings end up influencing the general electorate to vote the government out of office at the next available opportunity. In a democracy the extent and ways in which these different elements of intrastate accountability interact with direct forms of accountability to the citizenry becomes extremely important.

\subsection{On sanctions}

The above in turn suggests that it could be important to make distinctions not just between the possession/non-possession of official or formal sanctioning powers but also over the different kinds of damage that can be inflicted and by whom. This is not just a distinction between imposing sanctions and invoking others to impose sanctions. Crucially, neither of these necessarily means that the sanctions will actually be carried out: in Africa, 'slippage' is thought to be not unusual.

Informal and indirect sanctions are distinctive in that they may be triggered without the consent or even the intent of the original institution of accountability. Indeed voters may choose to take action against their political representatives because of what they perceive to be a failure of the official sanctioning mechanisms to follow through with inflicting justifiable punishment, provoked by evidence brought to light by the formal mechanisms for transparency and answerability.

\subsection{Accountability to society}

More wide-ranging than the idea of accountability to voters is the idea of accountability to society (social or societal accountability). This embraces a number of ways whereby social institutions and groups endeavour to monitor and reveal the performance of government, alongside but separate from the workings of the electoral process. Where 
citizens engage directly with horizontal accountability mechanisms in efforts to provoke better oversight of state actions, by-passing more formal procedures along the way, one source calls this diagonal accountability (DFID 2007). None of this substructure of accountability comprising the independent media and civil society associations is captured fully in the clauses of countries' constitutions, although the constitution might provide underpinnings in the form of guaranteed freedoms of association, expression and so on.

Political sociologists are likely to seize on the potential significance of societal accountability more readily than are legal scholars. Surprisingly, perhaps, Mainwaring (2003: 7), who is a political scientist, believes that because accountability implies not just answerability but also a legal obligation to provide answers and/or the institutional right of an actor to impose sanctions then the idea of societal accountability looks rather suspect. And yet as Smulovitz and Peruzzotti (2003) have countered, the people may wield a form of 'soft power'; their scrutiny can have material consequences for the politicians. The potential value of this to maintaining democracy is enhanced in the absence of effective parliamentary opposition to the government of the day, such as where one party is dominant (like the African National Congress in South Africa) or government is a coalition of all main parties (Kenya in 2008). However the practice of societal accountability may not be fully compatible with democratic accountability, once we note that civil society organisations themselves may well not be representative and few are democratically accountable; moreover private media's interests are driven by profit and can be politically very biased or highly partisan. Nevertheless the effectiveness of institutions which in principle do have formal sanctioning powers may depend at least in some measure on their standing and support from these and other actors in society. This is where Gloppen (2003) found the courts in Tanzania to be fundamentally weak, for instance. In contrast the role of independent budget groups in Africa generally (Krafchik 2005) and South Africa and Uganda specifically (Robinson 2006) are claimed to offer support that strengthens the budgetary oversight capabilities of parliament. In 2006 an Affiliated Network for Social Accountability in Africa (ANSA-Africa) was established jointly by the Human Sciences Research Council (South Africa) and the World Bank for the purpose of developing collaboration on social accountability ('demand-side governance initiatives') across Africa as whole.

Goetz and Jenkins (2004) detect from evidence in India a new accountability agenda in the making. This provides for a more direct role for ordinary people to demand accountability across a diverse set of jurisdictions, but in a radical departure from existing notions it does this on the basis of a more exacting standard of social justice than has applied hitherto. In their judgment India's power-holders are increasingly being held accountable to norms of social justice, which goes beyond the narrower confines of process integrity and the formal substance of the constitution. While it may be premature to say that something like this is taking hold anywhere in Africa, Klare's (1998: 150) description of 'transformative constitutionalism' in South Africa - 'a long-time project of constitutional enactment, interpretation, and enforcement committed...to transforming a country's political and social institutions and power relationships in a democratic, participatory, and egalitarian direction' - maybe comes close, by capturing the notion that adjudicative methods should contribute to egalitarian change. Certainly the idea of accountability to society becomes more complicated if a country's constitution makes a point of giving guarantees to certain groups in society such as women, ethnic minorities, indigenous peoples, and disabled persons so as to ensure equal - or, in the case of affirmative action/positive discrimination legislation, privileged - treatment

To sum up, democratic accountability can be understood in different ways: it encompasses answerability to the law and responsiveness to the people; it can entail both the direct and indirect application of sanctions, examples of which may vary greatly in severity and certainty of application. The conventional distinction between ex ante and ex post mechanisms of accountability can be supplemented by distinctions between intrastate accountability, electoral accountability, and accountability to society; external accountability adds yet a further, albeit non (or anti-) - democratic dimension. The constitutional and political relations that obtain between the different instruments of accountability may be as important as each institution taken singly. Although the idea of measuring democratic accountability in a country, or performing a country-based accountability audit, sounds attractive, before going on to conduct inter-country comparisons or construct an entire African league table, all such endeavours would be highly ambitious: the multi-dimensionality of accountability presents challenges as formidable as the disputations over its essential meaning.

\section{Constitutions and accountability}

In a state that adheres to constitutionalism the power of government must be sourced in the constitution. Nowadays this nearly always means a written constitution. Even in countries that do not have one such foundational document there are constitutional rules and conventions that have been codified in various ways. A constitution then is an instrument for making government accountable.

Although a word-by-word analysis of actual constitutions would probably show that few make extensive use of the word accountability, constitutions clearly do provide for and authorise institutions of accountability: they ground the powers of such institutions, most notably those that are supposed to hold the executive to account. However, constitutions do not implement themselves, any more than the fact that certain rights are enshrined in a constitution or 
accompanying Bill of Rights will guarantee that those rights can be exercised. Constitutions are implemented by and through the actions of the institutions they help create. And yet these very institutions are accountable to the constitution - their powers are limited and defined, even though the specification may not always be crystal-clear or precise. Thus while judicial power is normally considered the bedrock of constitutional protection- and to that extent its status is quite distinctive and superior to all the other institutions of accountability - even the courts are not above the constitution or the law.

Although in modern democracies constitutions and governmental accountability are intimately connected, the first is not a sufficient condition for the second. Other notable instruments of accountability are extra-constitutional: some may have been created separately by executive action or by legislation; others may be set up directly by initiatives of society. Political parties for example are central to making accountability arrangements work effectively but not all constitutions mention them. But of course such freedoms as speech, assembly, association and access to information, which tend to be written into the constitution or associated declarations of rights, are indispensable to helping extra-constitutional actors call people in power to account. The exact relationship between the constitutional status of an accountability instrument and its actual effectiveness is something that can only be determined empirically. In Africa a starting point is to discover whether the performance of roughly similar organisations (Human Rights Commissions for instance) in different countries or at different times varies significantly quite independently of their constitutional status, and to investigate the reasons.

\section{Constitutional choices}

The embedding of institutions of accountability in choices over the constitution cannot be understood fully without reference to how constitutional choices come about. The background situation that gives rise to an opportunity to make constitutional choices varies greatly, from peace to internal or external war, and from the confidence offered by a period of political stability to the catalyst provided by an experience of state collapse or the tribulations of a failing state. The African continent has examples of all of these in recent times.

Constitutional choices are always made by someone for some purpose. Bastian and Luckham's (2003:3) judgment is that 'aspirant democratic Machiavellis, who introduce or reform democratic institutions in specific historical situations, are just as likely to be swayed by short-term political priorities and demands from narrow political constituencies as by strategic visions of the nature and purposes of democratic governance'. That may be an exaggeration, but a reasonable assumption is that the constitutional choices will reflect the distribution of power existing in society at that time. In societies that have recently witnessed dramatic social and economic change or undergone political turmoil the new distribution of political power can be very different from the one that underpinned the previous constitutional order and its provisions on accountability. Violent revolution is not a necessary condition for this to happen, as South Africa's political transformation with the end of apartheid demonstrates.

However, an obvious question to ask where a new constitution emerges and is not then implemented in the way that was intended or expected is why? While one line of response could be to concentrate on what developments took place subsequent to the making of the constitution, another would be to look for reasons why the original choices proved unworkable - reasons that date back to the way in which the choices were first made, or the circumstances prevailing at that time. Some deviation in the course of implementation may be inevitable, but the presence or absence of birth defects also makes a substantial difference.

\subsection{Inevitability of constitutional change}

Constitutional choices and their effects do not invariably freeze the distribution of power, either among elites or between the elites and society. The institutional choices might be expected to cast a long shadow, because they create vested interests in maintaining those institutions and in resisting further change. However, the premise that institutions are 'weapons in the struggle' (Geddes 1996: 18-19) for personal and party political survival/advancement may not prevent actors other than intended beneficiaries taking advantage. Moreover the so-called 'transformative constitutionalism' (Klare 1998) is expressly intended to have consequences that will effect profound changes in the distribution of social and economic power, and thereby in political power, even though neither the constitution nor its makers probably envisage that the constitutional document itself will be altered in any fundamental way.

Where the patterns of power in society do change over time, the groups or forces that are on the rise may well seek to bring in constitutional changes that reflect more accurately the new situation. The political forces that were previously dominant too might seek constitutional changes, in order to further strengthen their position where they see threats developing on the ground. The different scenarios serve to remind us that although in Africa the task of holding the executive (presidential power specifically) to account tends to be seen as one of the major political challenges, the requirement for democratic accountability must extend to other organs of state too, the legislature included. For example government should ensure that parliamentarians make only a proper use of the publicly funded allowances that are in place to subsidise their legitimate expenses. A national audit office will often have the power to scrutinise the 
accounts of other state institutions of accountability.

A special situation where the constitutional bargain is likely to obsolesce over time, even where the distribution of power in the country that gave rise to it remains the same or is reinforced, is where the nationally dominant actors did not at first obtain everything they wanted but had to make concessions as a result of international pressure. Zimbabwe and the Lancaster House Agreement (1979) is a specific example. Others are post-conflict settlements where the United Nations for instance has helped to broker the peace and mediate a political solution. The external actors relax as their attention then moves on to other theatres. Continued external intervention in their domestic politics is not usually accepted by sovereign independent states, even if support for the norms of democracy or human rights would seem to make it desirable in cases like Zimbabwe or Sudan. However it is also the case that constitutional choices agreed by domestic political forces may subsequently come under outside pressure to adopt or adapt to evolving regional and global understandings - including on such matters as fundamental rights - even in the absence of manifest implementation failure. Taking on the obligations of membership of the International Criminal Court (currently 29 African states are signatories) actually introduces a new external accountability.

\subsection{Birth defects}

A scenario that can arise almost anywhere is when the locally dominant actors' own understanding of the kind of constitutional choices that would serve their own or the country's interests changes after the constitution has been put into effect. This may be just a consequence of a learning experience. Or it could be due more to developments in the surrounding political, social and economic circumstances. Either way, it can lead the elites to seek to reopen the process of constitution making. In the more extreme situations a constitution may simply prove impossible to implement in the way that was intended or is incapable of realising the desired effects. How can this be explained?

The actors who are designated to put constitutional choices into practice and those who actually implement them will not coincide for long with the actors who bore responsibility for the initial decisions. The institutions and people in charge of implementation may have been given too few powers. They may not have the requisite competence and expertise. Their resources may be inadequate - a common problem in Africa. Instances of maladministration can owe to these shortcomings without wilful negligence or intentional failure. But it is also entirely plausible that institutions and actors will come to acquire interests that conflict with the agendas that were uppermost in the constitution-making process, if only because the original constellation of political forces fractures or constitutional implementation becomes caught up in political conflict among rival groups, as happened in newly independent Zimbabwe. For all these reasons constitutional choices and the structures they create may soon come to be seen as flawed, or are disregarded or disowned.

Beyond the question of resources and design-related explanations for 'slippage' in constitutional implementation, then, lies the issue of 'ownership'. This in turn is closely connected with the process by which the decisions on a constitution emerge and the way the choices were sealed. If the constitution-making process has been confined to just a small political elite, especially one that is unrepresentative, then persuading society at large to accept ownership could be problematic. The people's willingness to cooperate in the smooth day-to-day running of the institutions that are essential to making the constitutional choices a success cannot be guaranteed. They may simply carry on their lives in ways that leave the constitutional choices redundant. More radical strategies of resistance to constitutional implementation develop. This scenario is captured by the notion of disengagement from the state, and resort to parallel structures of authority even. In many parts of Africa the development of an informal or second economy that defies official attempts at regulation is widespread. Tax evasion is a well-known manifestation: it takes encouragement (if not legitimacy) from widespread suspicion that there is too little accountability in the way the government handles the public finances.

In consequence informal institutions - whether defined in terms of shared values or shared expectations - can have a heavy bearing on how the formal institutions actually work, causing them to depart from their official purpose and producing results that were not intended by the formal institutional design. The political science literature on Africa suggests that informal institutions comprising neo-patrimonialism and patron-client networks are widely and deeply entrenched. However, although the burden of commentary tends to be highly critical, Helmke and Levitsky (2004) rightly draw attention to the potential for exploring the more constructive side: informal structures that lend weight to compliance with the formal institutions and give them stability, or stimulate reform efforts to improve on the design of poorly-performing formal institutions and, even refine the constitution itself.

The merit of 'ownership' is widely cited in a variety of literatures on problem-solving approaches in political as well as economic development. It is another way of saying that inclusive participatory arrangements can give processes of deliberation access to a broad base of knowledge; even more important they help create a strong sense of commitment to the outcome. That means a feeling of obligation to make the solutions work. A participatory approach to constitution-making seems then to be an obvious recommendation (see for example Ghai and Galli 2006). However there is little consensus on how inclusive and how participatory constitutional processes must be: such details usually escape close specification, notwithstanding their importance. Listening to the people is one thing; envisaging them 
having the power to sanction is another. One of the more familiar devices in this context is the referendum on a constitution in its entirety or on selected proposals for constitutional change. However African constitutions vary widely in how far certain provisions in the constitution such as those pertaining to basic rights can be altered, and the procedural requirements. But even if 'ownership' secured through inclusive participation in the process of constitutional choice-making really is a necessary condition for constitutional implementation to succeed, it is not a sufficient condition.

In sum, the degree to which constitutional choices are implemented will bear some relationship to how they were made, by whom and under what circumstances. As to what that relationship is, only wide-ranging comparative research can provide the answer. In the meantime informal institutions that are not codified in the constitution may shed much light on how formal institutions of accountability mandated by the constitution perform in practice.

\section{Constitutional choices and institution building}

Even after separating out the occasions where reforms officially styled an interim constitution have figured in processes of political change, constitution building is unlikely to be a one-off event confined to a single instant in time. In fact the idea of constitution-making appears to shade into constitution-building, which seems not to have a sharply separate identity. In Ghai and Galli's (2006: 9) words, constitution building 'refers to the process whereby a political entity commits itself to the establishment and observance of a system of values and government...Constitution-building stretches over time... an almost evolutionary process of nurturing the text and facilitating the unfolding of its logic and dynamics'. Clearly this process can be as important as the act of writing a constitution. At minimum it will include formal amendments made in accordance with procedures laid down in the constitution - although the possibility of there also being unconstitutional constitutional amendments cannot be discounted, and as Hilbink (2008: 243) observes, 'really does set constitutional court judges up as guardians'.

\subsection{Judicial interpretation}

Building on the constitution can happen in several ways. Most notable are processes of judicial and constitutional review (by the judiciary and by a special constitutional court respectively), leading to constitutional interpretation. Review includes rulings in cases that are brought under and, perhaps even against the constitution, and cases brought against institutions of accountability established by the constitution. The last can include the parliament, whose legislative provisions might be annulled by the courts exercising the power of judicial review. In Africa there are at least 29 constitutional courts and 12 countries with judicial review (Sweet 2008: 221).

The large literature on judicial interpretation naturally touches on the potential for conflict between the idea of judicial independence and the accountability of the judiciary itself, or what is sometimes called the problem of 'second order accountability'. The question comes to life most intensely, perhaps, in cases where interpretation of the constitution collides with an exercise in defining the national interest, which is an area normally deemed the prerogative of (elected) politicians. Here the question of who determines whether the issue at stake really does concern the national interest is as crucial as determining how far and in what way the national interest is being put at risk. The usual line of defence for the courts when charged with being unaccountable lies in being transparent, in the sense of sharing the legal reasons for their judgments and showing imperviousness to politically partisan or ideological grounds. A similar concern for transparency can be commended to other instruments for making government accountable, even where the requirement or the potential to explain their actions in apolitical terms need not apply. Thus expectations in regard to how an Anti-Corruption Commission, say, must couch its findings will differ from the exercise of legislative oversight that endeavours to bring the executive to account for its political decisions.

\subsection{Winning and losing in politics}

In politics a rational expectation is that organisations including those created by the constitution as instruments of accountability will aim to make a creative construction of their powers, for bureaucratic as well as political reasons. Put differently, they are budget maximisers. Of course not all such institutions will do so with equal vigour or skill: personal factors and quality of leadership may be decisive, and no constitution can predict these. Indeed, in so far as there is a system of checks and balances among institutions of accountability it is plainly impossible for them all to increase their power vis-à-vis the rest at the same time: jurisdictional conflicts and 'turf wars' have losers as well as winners. However it is quite feasible for the absolute power of the organs of state as a whole to grow in relation to the freedom of the citizens, without anti-democratic implications. This can happen even while the balance of power between institutions shifts and some institutions see their former position in the institutional hierarchy descend in relative terms.

Changes like the above can happen following a formal amendment to the constitution, or because of separate legislation or due to less formal developments. But none of this necessarily betokens a failure of constitutional implementation. On the one hand constitutions can intentionally allow for such developments. The periodic updating of a country's constitution may be a normal feature of constitution building: it is not necessarily a sign of a constitution under stress. 
Yet it is important to distinguish situations where changes to the power of the state and in relations among institutions of accountability offer clear evidence of limitations and defects in the constitution. Reading the situation correctly calls on political as well as legal judgment; accuracy might require the benefit of hindsight.

Of course what should be judged a weakness in the constitution and what counts instead as a failure of implementation could be hard to disentangle. To illustrate, an institution might have been given powers that are inadequate to the functions it is mandated to perform but this dilemma becomes apparent only with experience and the passing of time. More easy to read are situations where constitutional provisions are altered largely in order to meet personal or partisan political ambitions. The very principle of constitutional rule would then appear to be in peril. A prominent example in Africa is where term limits on holding presidential office are removed or relaxed (attempted examples range from Nigeria to Malawi) or conversely tightened (Zambia in 1996) so as to serve an ad or contra hominem cause respectively. But even here it may be argued that making correct use of the established legal procedures for changing the rules is a democratic advance of sorts: it reinforces respect for the rule of law, and may successfully curb overweening political ambition. Posner and Young (2007) argue in this way when calculating that of the 18 directly elected presidents in Africa who faced term limits in 1990-2005, nine stood down and nine attempted to change the constitution, of whom only six were successful.

A moot point is how many of the accountability institutions must be judged wanting in their performance, and to what extent, before we can infer that constitutional implementation has failed or there is a fundamental weakness in the constitutional design, or both. A systematic examination of the evidence is likely to reveal that different institutions vary in their track record and their effectiveness fluctuates over time, both inside a country and when considered across comparable countries. If some accountability institutions perform badly in the presence of other institutions that seem to perform quite well then the reasons for the discrepancy certainly merit close inquiry. But a prior question will involve determining whether heavy traffic through instruments of accountability, the Office of Public Prosecutor or Ombudsman for example, denote a failure of constitutional implementation or, on the contrary, furnish evidence of foresight in the framing of the constitution and give testimony to the public's confidence in their efficacy.

More serious still would seem to be the formal states of emergency that involve suspension of provisions of the constitution, especially those which give effect to certain civil liberties or political rights. But if these departures are declared - and subsequently brought to an end - in line with the terms of the constitution and the political consensus is that the situation provides adequate justification (e.g. force majeure) then neither the constitution nor its implementation may be seriously at fault. In practice, however, full consensus usually does not exist; and responsibility for bringing about the situation that is advanced as grounds for calling the emergency is often disputed. The two emergencies called by President Chiluba in Zambia in the 1990s are examples. What is less ambiguous and more easy to pass judgment on is where the mechanisms of accountability themselves are subjected to arbitrary political interference. Nepotism and the making of partisan political appointments (and dismissals), attempts at bribery and other external pressures such as harassment or intimidation are examples of what is sometimes called 'politicisation' - a pejorative term that in theory could be used in relation to all kinds of accountability institutions.

Executive encroachment apart, the formal legal and actual political relations between the different institutions of accountability and the way these relations work out in practice are crucial to the larger question of how accountable the state is to society. The role of the legislature is usually thought to be paramount here, because of its place at the nexus of vertical and horizontal accountability. Legislatures are pivotal to the intrastate accountability of the executive and (via the electoral sanction) its accountability to voters too - although more so in parliamentary systems and hybrid variants than to systems where an executive president is directly elected. But while all the mechanisms of accountability are supposed to be checks on the abuse of power (not just by the executive but by other state organs too) there is no presumption that they always can or should try to prevent an increase in concentration of power in the hands of the state. In other words, the stipulations for democratically accountable governance and a well-functioning constitution tell us nothing about how large or small the state should be. In what measure the state should take on responsibilities for managing the economy, for example, or what the optimum size of the law enforcement agencies is, are political and technical decisions more than constitutional issues. The answers will vary greatly depending on the circumstances of the country and on the values of its people and their political representatives. Thus, while the typical picture that is painted in Africa of rule by 'big men' may look anathema to the end of constitutionally limited government, that end does not of itself preclude the possibility that 'big government' might be (judged to be) desirable. Africa's cult of the 'big man' may be problematic for accountability, but small government is not necessarily best for Africa.

To summarise, just as constitutional choices do not cease with the making of the constitution, so constitution building both shapes and is shaped by processes of constitutional implementation. Constitutional choices lay the groundwork for institution building but they offer no guarantee of good institutional performance. In a democracy the actual performance of institutions of accountability is likely to be a notable influence on public satisfaction or dissatisfaction 
and hence on the likelihood of (renewed) demands for constitutional change.

\section{Stages of constitutional implementation and the development of a constitutional culture}

Although constitutional implementation does not happen all at once it could be useful to distinguish analytically at least two (maybe overlapping) phases. After the constitutional document as such has received final authorisation, the first real stage of implementation involves setting up the organisations and developing the rules and procedures that were designated in the constitution. The standing orders of parliament are an example. The constitution and other foundational legislation may not be entirely clear about translating words into deeds. But such matters as who controls the appointments to agencies of accountability and on what terms and conditions and who decides the budget can be crucial to subsequent performance. Implementing the constitution may also require the law-makers to remove old laws from the statute book or replace existing institutions whose existence could frustrate the new constitutional order. Not all the contradictions may be apparent immediately; but if action is delayed because the legislature is already overburdened by a large policy reform agenda then conflicts can be expected to emerge later.

The second stage of implementation comprises the actual performance of the new organisations. This may have to be measured against benchmarks which are constructed only after the institutions were created - benchmarks that may end up being devised whole or in part by those very same institutions. The designing of performance indicators can have major implications for any assessments that are carried out later. In an African context it is unwise to assume that all the requisite information will be collected, stored and made easily available. Deficiencies here, whether due to lack of resources, negligence or more sinister motives can have debilitating consequences both for accountability and research into the subject later.

\subsection{Constitutional culture}

The theoretical meaning of 'constitutionalism' may be contested (Sweet 2008: 219-20) just as is the definition of accountability, but in practice a distinctive aspect of constitutional implementation that may be crucial to how well the institutions of accountability perform is the development of a constitutional culture. While not a stage in constitutional implementation this can be considered an important aspect of constitution-building in the largest sense. It is a process that may be under way before the emergence of a democratic constitution. For instance concerted efforts by lawyers to shape something like a human rights culture might start long before the adoption of a constitution that finally secures legal recognition for those rights.

A constitutional culture is not synonymous with a democratic political culture (sometimes called 'civic culture'). There can be respect for a constitution that is not a democratic constitution, just as there can be a strong parliament whose procedures and whose members do not respect democratic values. But in a constitutional democracy the development of a constitutional culture would appear to be indispensable to the stability of constitutional rule, even though it cannot predict the constitution's adequacy as an instrument of political accountability. Also, it involves more than just knowledge of the constitution and the values it purports to represent. Attitudinal variables, most notably respect for constitutional rule are integral. And in turn that should protect the agencies of accountability from arbitrary external interference in their internal working. That the attitudes shown by constitutional lawyers and leading politicians obviously matter a great deal here does not mean the development of a constitutional culture throughout society as a whole is less important - although longer term cultural change there may take its cue from the constitution and the conduct of the institutions and leaders' behaviour. However, acceptance of the permanence of constitutional rule - of the idea that rule should be and must continue to be in accordance with the constitution - does not require complete agreement with all the features of the constitution. Rather it means recognition that alterations should be made only through the properly sanctioned procedures.

A point worth repeating is that constitutions empower the institutions of government and may even bestow extensive and far-reaching powers on public officials, as well as introduce mechanisms of restraint. Even so, a constitutional culture recognises that the constitution is not the property of those who made it or of the people who are currently in power. The development of such a culture, then, implies an acknowledgment that governing must be rules-based. And with the culture comes the habit of looking to the constitution to help resolve certain kinds of problem, to head off certain kinds of dispute. But far from rendering politics redundant it serves to make democratic politics possible; it enables disagreements to be resolved by political or other peaceful means. Thus while constitutional rule needs experts in public law it does not eliminate the need to find political solutions to political problems. It can enhance the role that elected politicians play even as it aims to constrain (and does constrain) the way they conduct their activities.

A constitutional culture of this sort can extend well beyond the sphere of the state, and encompass a wide range of political and social organisations. For example it is common for political parties, labour organisations and many types of non-governmental or civil society organisation to have a constitution, 'articles of association' or set of rules. These devices structure their internal affairs and determine major issues relating to who in the organisation can do what. A culture that respects constitutional rule for the entire polity should benefit from there being similar agreements 
embedded in a variety of such associations. Membership of international bodies that require respect for their constitution can be yet another source of reinforcement.

\section{Institutional performance and constitutional implementation}

While the impact that constitutional choices have on the prospects for implementation with respect to the performance of institutions of democratic accountability is a question worth pursuing, a parallel and no less intriguing question is what lessons implementation tells us about the scope for making effective choices in the first place. To address this requires passing judgment on institutions of accountability, but that may be no straightforward matter. Even with reliable information the same body of evidence is often capable of different interpretations, akin to the 'glass half empty, half full' metaphor. And the correct inference to draw from weak accountability may not be obvious: is it unsatisfactory implementation, or defective design, or some third factor outside both of these? How robust is the view (from a legal scholar writing about Africa) that many legal texts particularly constitutions are 'shot through with apparent and actual gaps (unanswered questions), conflicting provisions, ambiguities and obscurities' (Klare 1998: 157)? And how many of the difficulties can be put down to the continuing presence of a substantial body of traditional law? To illustrate, although South Africa's constitution rules out arbitrary discrimination against women, the institution of customary law which is recognised in the constitution combined with traditional patterns of land ownership rights appears to marginalise women in this domain.

A constitution that for any or all of the above reasons fails in the sense of not giving rise to effective institutions of accountability might be rescued by judicial adjudication or other means of effecting constitutional change that were envisaged in the constitution, whether on a gradual incremental basis or by occasional big set-piece events. Clearly the weak performance of one or another institution of accountability does not necessarily imply that the constitution or implementation has failed. Problems experienced in setting up organisations for rendering government accountable and the shortcomings that come to light in their operation later may owe to many factors, some that constitutional bargains can never control and which could not have been foreseen (but which might surface as a consequence of judicial review). In order for constitutional implementation to be effective, however, the legal means to address such weaknesses must be identified in the constitution. At minimum they should be enabled by the constitution.

Neither constitutional remedies nor better resourcing, improved training and higher levels of remuneration at the institutions of accountability are likely to remedy all the shortcomings in implementation. As shown later, contextual issues to do with the political system can bear a heavy responsibility. A focus that examines just the internal workings of institutions and ignores their environment would be too limiting a site of explanations and potential remedies.

\section{Constitutional failure in democracies: some explanations}

Changes to the constitution do not mean implementation failure any more than implementation failures will necessarily bring about formal changes to the constitution. But failures of implementation, a failing constitution, and inability to develop a culture of constitutionalism are all signs of constitutional weakness. The degree to which they are seen to be politically significant and the reasonings about why that matters are likely to be context sensitive and case specific. In many cases the evidence of failure will be uneven, although constitutions sometimes do fail absolutely. And causal connections between the different weaknesses are worth looking for. From what Ghai and Galli (2006: 17) say constitutions are especially vulnerable in complex and divided societies, where 'a new constitution is like a delicate plant which needs careful nurturing' One of the questions that empirical research should be able to settle is whether the incidence of constitutional failure is inversely related to the provision for judicial or constitutional review and other ways of lawfully amending the constitution. Of course there must also be a point beyond which the ease of change and constant tinkering with the constitution or gyrating interpretations signify a failed constitution and, possibly, the absence of a constitutional culture too. But it is worth considering that not all constitutional failure is necessarily bad: the abandonment of bad (not to say undemocratic) constitutions in Africa has been a positive development. But equally, not all democratic constitutions are meant to succeed: some of the contracting parties at least may be unshakeably committed to agendas that are bound to prove fatal to the constitution sooner or later.

Approaches to explaining constitutional failure can be divided into broad, analytically distinct clusters: internal problems (poor design); process-related weaknesses (how the choices came to be made, by whom and the historical background); and context-related (unfavourable features of the larger political system, the economic environment). The explanations are not mutually exclusive and their incidence may be closely connected to one another; different permutations of reasons might be required in different cases.

\subsection{Design weaknesses}

Lack of clarity, confusion, incoherence, inconsistency, contradictions and incompleteness in the basic documents can all fatally undermine a constitution. While some such shortcomings might have to be knowingly accommodated in the constitution-making process in order to reach a political settlement acceptable to all, they can undermine democratic accountability later. The cascade of accountability between ministers and officials may be poorly defined, creating 
opportunities for one set of actors to hide behind another; alternatively the same actor may be invested with multiple lines of accountability that make it impossible to honour each and every one. In Zambia for example the constitutional arrangements for effecting collective and individual ministerial responsibility are weak, but they have provided the executive with convenient grounds for resisting the introduction of more robust arrangements (Burnell 2003: 56). In general terms the impact that key constitutional omissions have on the course of future politics could be just as important as anything the constitution actually prescribes, although like so much this insight too awaits confirmation by broad-based empirical research. At the same time some vagueness in the wording of a constitution could allow the flexibility that future generations require if arrangements are to be adaptable to changing circumstances and avoid the risk of a growing irrelevance or complete break-down.

\subsection{Inauspicious origins}

Inauspicious circumstances surrounding the making and building of a constitution can be responsible for weaknesses that persist or come to a head long afterwards.

For example, in societies that have been rent by violent conflict the act of creating a new constitution is sometimes approached primarily as a means to sealing the peace, in haste and with insufficient reflection given to the needs of the longer run. Reynolds (2002) explored these dilemmas through an examination of such institutions as electoral arrangements and multi-level governance. Solnick (2002: 205) summed up the predicament well when he said that theorists of constitutional design 'must consider not only whether a particular institutional design is attractive for a given polity but also whether the transitional environment makes it likely that the given design would be adopted'. Awkward compromises can become the order of the day - to be repented at leisure later. International actors involved in brokering the peace may set timetables for completion that are governed by their own interest in making an early exit. External advice on the constitutional substance may carry undue weight even though not wholly appropriate to local circumstances - increasing the risk of what Bastian and Luckham (2003: 314) called an 'iron law of the perverse consequences of institutional design'. Post-Saddam Iraq is perhaps the most prominent example of this kind of scenario currently being played out, with consequences that could yet bring the state's destruction, but Africa has examples too.

\section{3 (Pre)Historical path dependence}

Throughout much of Africa the idea that democratic constitution-building is hampered by inauspicious origins takes on special resonance connected with the time before independence.

Colonial rule was not a good introduction to democracy. One view is that the institutional and cultural legacy has left an indelible impression on the way African societies view government today. Where local legislatures or other political instruments of consultation did exist in the colonial era they were advisory at best, possessing no real oversight powers. Modern ideas of democratically accountable government and many of the devices for translating that idea into reality (institutional checks and balances; the concept of a 'loyal opposition', and so on) can seem foreign in their inspiration and lack local roots. In the colonial era the authorities governed as they saw fit, which meant paternalism at best, or self-serving authoritarian rule at worst (at its very worst predatory and extractive, as in the Belgian Congo). Bouts of de jure one-party rule and/or military (-backed) government after independence did little to implant the idea that society should hold government to account. Constitutions were repeatedly ignored, amended or replaced when it suited the executive. Old ways of thinking die hard. Indeed, where colonial power governed through indirect rule, historical path dependence may reach back even to pre-colonial exemplars, which resembled not legal-rational authority but traditional power structures and patterns of behaviour such as (neo-) patrimonialism, that persist to the present day.

Mohamed Salih $(2005: 8-12 ; 249)$ provides an example of this perspective when he argues how the servile relationship of parliamentarians to the head of government and ruling party in Africa's former one-party states (Tanzania and Zambia for instance) still haunts African legislatures in today's multi-party dispensation. This is reinforced where a dominant party bears the credentials of a liberation movement, as in South Africa, Namibia and Zimbabwe.

One drawback with this line of analysis is that the experience of constitutional rule and democratic government in African countries with a broadly comparable exposure to colonial rule (the same colonial power, even) varies greatly. Countries like Botswana and Mauritius have been stable democracies since independence; Ghana is now one of Africa's leading liberal democracies although before the 1990s it endured successive coups and military rule; Zimbabwe has experienced increasing autocracy and erosion of judicial autonomy and rule of law. Notions of path dependence may not be able to explain fully such diversity of trends.

\subsection{Participation and its drawbacks}

If constitutional proposals can generate controversy then the same is true of the process by which constitutions become law. On the surface the failure to adopt a participatory approach to making constitutional choices would seem to deny legitimacy to the outcome. Participation should generate stakeholders in ownership. Legitimacy and ownership ground a commitment to abide by the constitutional bargain, a willingness to cooperate in trying to make it work. This reasoning rather than design weaknesses could explain why some constitutional settlements that relied heavily on 
international cajoling may face compliance problems later (Harris and Reilly 1998: 348).

However, the value of participation should not be viewed uncritically (Cleaver 1999). And as Ghai and Galli (2006: 5; 15) note, the people may pull in different directions, ending up with a constitution that is complex and hard to implement - increasing the chances that the politicians will disown the constitution later. In Kenya politicians across the board backed away from the findings of widespread consultation on constitutional reform when they realised that the peoples' demands would make them more accountable (Cottrell and Ghai 2007). Constitutional referenda that reveal society is badly divided create further problems. Ghai and Galli (2006:11) note correctly that even an inclusive participatory process that is free of manipulation by self-serving leaders will not guarantee implementation if the constitution itself does not open up spaces and mechanisms for the people to engage in public affairs thereafter. A sense of ownership by founding fathers is not obliged to travel down subsequent generations, for whom the constitutional settlement is something to read about in history books, not a personally lived experience.

In addition to ownership and opportunity society must of course be capable of rising to the challenge of implementation too. But amidst all the uncertainty one moral that probably commands broad agreement is that politicians can be counted on to wreck a constitution that is made by lawyers alone. In other words, in order for politicians to make a success of constitutional implementation the constitution building must be a political process, regardless of how broad or narrow is society's participation. The intelligibility of constitutional documents and mutual comprehension between lawyers and politicians are vital considerations, but their existence should not be presumed. Even so, a useful exercise would be to map the routes by which Africa's present day constitutions came about and match the participatory content of the process against the results framed in terms of effective implementation, public satisfaction, and the extent to which the constitutions have since undergone significant change by way of judicial review, referenda or other forms of amendment.

\subsection{Unfavourable economic context}

Structuralist arguments ground the weaknesses found in both accountability and constitutional implementation in poverty in society and restricted opportunities for economic betterment. Extensive or deep socio-economic inequality are reinforcing factors. Circumstances like these are conducive for politicians - especially those with access to government funds - to try to secure votes through offering patronage. In Africa it is often said that society's expectations of their elected representatives focus on meeting constituents' (in other words, clientelistic) demands for public spending addressed to sectional and particularist needs. Notions of holding the executive to account for serving the larger public good come far behind. Economic scarcity also fuels the practice of bribing government officials, which may corrupt even officers working in the intrastate agencies of accountability. Accordingly anti-corruption commissions have become widely established in Africa: they are a major part of the 'good governance' agenda. But senior politicians often escape serious sanction even where corruption at low to middling levels in the bureaucracy is pursued, except where corruption charges are yoked to partisan or personal political feuds.

In many African countries the instruments of accountability (anti-corruption commissions included) have difficulty competing for resources with stronger claims on the state's limited revenue base. Severe under-funding is commonplace, and can be deliberate. However, although sustained economic development might offer a panacea it is also true that some countries which are marked by the 'resource curse', Angola for instance, also find that accountability is undermined. Where thanks to the windfall rents from a valuable commodity like oil (or foreign aid) society is not taxed heavily, a strong pattern of evidence suggests that the public's demands for accountability tend to be weak (see Rakner and Gloppen 2003). That said, Botswana is an example of a country that has a relatively favourable record of democracy and effective governance while enjoying great benefits from diamonds exports. And Ghana receives substantial international aid in part because the donors are now relatively satisfied with the country's political and economic management. Once again, then, only more extensive empirical testing can shed further light on theoretical claims that link the record of accountable governance and sound constitutional implementation with economic and financial conditions. Nevertheless it is probably no coincidence that Botswana and Mauritius both of whom have enjoyed sustained development appear to be among the countries with the most enduring democratic rule.

\subsection{Unhelpful party politics}

Democracy is not defined solely in terms of elections and the competition for votes. But the political party system and the way the parties are structured internally are important features of representative democracy that can have a significant bearing on constitutional implementation and accountability. In countries like South Africa and Mozambique the constitution explicitly guarantees a space for political parties (via the Bill of Rights); in Nigeria a regulatory framework prohibits narrow ethnic or regionally based parties. Basedau et al. (2006: 630) calculate that in 22 African states there are bans on particularistic parties, the majority being written into the constitution. The legal case for constitutionalising all of Africa's political parties in such a way as to enshrine both their responsibilities and their status and rights has been made in Africa by Fombad (2007). 
The political science literature on political parties identifies at least three situations that can be problematic. The first is where one main party is dominant - a situation where Fombad (2007) says constitutional guarantees and protection of the rights of parties are especially needful in order to prevent the danger of majoritarian tyranny. A second, less prominent in Africa is when the party system is highly fragmented and unstable (as in Kenya and Malawi), which makes it difficult for parties to connect state and electors in a clear and sustained way. A party escapes being held to account for governance by shuffling onto others the responsibility for achieving results. A yet third situation, which may also be found in the presence of the other two, is where political competition is strongly oriented around personalism and clientelistic behaviour. Throughout much of Africa parties function more as vehicles for the personal ambitions of political leaders (often a major source of the party's funds) than to pursue a programmatic mission, thereby removing one of the anchors of public accountability. Parliamentary oversight is usually one of the most visible casualties, where according to Mohamed Salih (2003: 253) competitive politics 'is the critical factor'. In some cases the party (system) weaknesses can be traced back to the electoral system. For instance proportional representation list systems translate into strong central control of the elected representatives, as in the African National Congress (ANC): by 2001 it seemed the ANC would no longer permit 'even internal debate about its lack of internal debate' (Butler 2005: 732). In a dominant party system presidential power is the beneficiary. Political interference in the electoral process can be another contributory factor - where the courts often become involved in passing judgment. Floor-crossing in the legislature also can have a bearing on the ability of opposition parties to remain competitive between elections: constitutional rulings on this in Malawi and South Africa have caused controversy. But how far all the mechanisms of horizontal or intrastate accountability can compensate for the drawbacks of a weak or non-competitive party system has to be established by more detailed research.

\section{Conclusion}

A recent attempt to investigate democratic accountability in Latin America said that 'the meaning of accountability is about as muddled as concepts get in social science' (Mainwaring 2003: 6). The idea of constitutional implementation has received much less attention in the (political science) literature and is similarly obscure. A major source of confusion for accountability is the endeavour to capture both (il) legality or (un) lawfulness and a more strictly political relationship. A parallel source of confusion in regard to implementation is the sense that constitutional choices do not stop with the making of the constitution. Instead they carry on into constitution-building through the ways in which a constitution is revised, interpreted and reinterpreted and applied thereafter and the development of a constitutional culture.

Accountability and constitutional implementation occupy a very broad terrain; clearly, relations between them are complex. Sweet (2008: 235) gives a clue to the lie of the land when he states that the reason why some countries are able to fulfil 'the conditions necessary for effective constitutional review is an important question that scholars have not been able to answer'. Many more questions just as relevant as Sweet's obtain and still await convincing answers. A manageable research agenda that aims to draw on the combined insights of legal scholarship and political science would have to select its focus carefully. An obvious starting point would be to catalogue what the region's constitutions actually say about accountability. A census of the mechanisms for accountable governance and identifying how far they reflect constitutional choices or conversely arose outside that framework could be the next systematic knowledge-gathering step. Comparing the background political circumstances and the process by which the present generation of constitutions came to be made, and assessing the performance of accountability instruments against an objective body of indicators in the light of that information, represents an ambitious but worthwhile task.

For some analysts it perhaps goes without saying that the 'accountability deficit' should be seen as 'a product of feeble sanctions' (Mainwaring 2003: 22). But is it really the case that the existing sanctions are inadequate, or does the problem not lie more with incentive structures and the reasons for weak enforcement? The motto 'prevention is better than cure' may have much to offer here: in the long run sound constitution-building on the ex ante side could prove more cost-effective than relying ex post on punitive applications of tougher laws. And while full accountability is an ideal that can never be achieved anywhere, that goal might not be desirable anyway. Just as Lonsdale's (1986: 129) pronouncement on Africa (made more than two decades ago) has validity still today - 'however much accountability may be a universal value, in actual political practice it is continually striven for and obstructed rather than achieved' - so there is merit in Schedler's (1999b: 19-20) more recent reminder that accountability is about rendering power to account, not about eliminating or substituting for power.

Governments, especially democratically elected governments must be allowed to govern. The implication is that power-holders need to have powers to exercise; and must enjoy some discretion. The scope to exercise choices means an opportunity to make mistakes - which is why adequate institutions of accountability must exist and function well. But we cannot expect those institutions to eliminate the condition that makes their existence necessary. This reflection comports with the reasoning that says there can be no such thing as a perfect constitution. Implementation failures and the response they provoke, then, may be viewed at least in part as an ineluctable form of market correction: they are 
ways of enabling constitutions to be kept relevant and alive. That constitutional implementation and accountability will exist in tension may be normal. The prize is to understand what can make this tension work best in terms of what society expects from democratic governance. The idea of governing in accordance with the spirit and not just the letter of the law is an old one: it could mean that no more weight should be given to largely procedural-based measures of accountability than is given to accountability tests related to constitutional process, performance and results.

\section{References}

Basedau, M., Bogaards, M., Hartmann, C. and Niesen, P. (2006). Ethnic party bans in Africa: a research agenda. German Law Journal, 8, 617-34.

Bastian, S. and Luckham, R. (Eds.)(2003). Can Democracy be Designed? London: Zed.

Burnell, P. (2003). Legislative-executive relations in Zambia: parliamentary reform on the agenda. Journal of Contemporary African Studies, 21:1, 47-68.

Butler, A. (2005). How democratic is the African National Congress? Journal of Southern African Studies, 34:1, 719-36.

Cleaver, F. (1999). Paradoxes of participation: questioning participatory approaches to development. Journal of International Development, 11: 4, 597-612.

Cottrell, J. and Ghai, Y. (2007). Constitution making and democratization. Democratization, 14:1, 1-25.

DFID (Department for International Development, UK government) (2007). Governance and Transparency Fund.

'Thinkpiece' memo. 'Governance and transparency - some thoughts!'Available: http://www.dfid.gov.uk/funding/gtf-guidelines (May 29, 2008).

Dunn, D. (1999). Mixing elected and nonelected officals in democratic policy making: fundamentals of accountability and responsibility. In A. Przeworski, S. Stokes and B. Manin (Eds), Democracy, Accountability and Representation. Cambridge: Cambridge University Press, (Chapter 10 ).

Economic Commission for Africa (2005). African Governance Report 2005 (Addis Ababa: ECA).

Fombad, C. (2007). Challenges to constitutionalism and constitutional rights in Africa and the enabling role of political parties: lessons and perspectives from southern Africa. The American Journal of Comparative Law, LV:1, pp. 1-46.

Geddes, B. (1996). Initiation of new democratic institutions in Eastern Europe and Latin America. In A.Lijphart and C. Waisman (Eds.), Institutional Design in New Democracies: Eastern Europe and Latin America. Boulder, CO: Westview Press, (Chapter 2).

Ghai, Y. and Galli, G. (2006). Constitution Building Processes and Democratization. Stockholm: International IDEA.

Gloppen, S. (2003). The accountability function of the courts in Tanzania. In S. Gloppen, R. Gargarella and E. Skaar (Eds.), Democratization and the Judiciary. The accountability function of courts in new democracies. London: Frank Cass, (Chapter 7).

Goetz, A-M and Jenkins, R. (2004). Accountability. In A. Kuper and J. Kuper (Eds.), The Social Science Encylopedia $\left(4^{\text {th }}\right.$ ed.). New $\quad$ York: Routledge. Available: http://www.bbk.ac/polsoc/staff/academic/rob-jenkins/accountability-social-science-encyclopedia-04 (May 29, 2008).

Harris, P. and Reilly B. (Eds). (1998). Democracy and Deep-rooted Conflict: Options for Negotiators. Stockholm: International IDEA.

Helmke, G. and Levitsky, S. (2004). Informal institutions and comparative politics: a research agenda. Perspectives on Politics, 2:4, 725-40.

Hilbink, L. (2008). Assessing the new constitutionalism. Comparative Politics, 40:2, 227-45.

Klare, K. E. (1998), Legal culture and transformative constitutionalism. South African Journal on Human Rights, 14, 146-88.

Krafchik, W. (2005). Can civil society add value to budget decision-making? A description of civil society budget work (International Budget Project). Available: http://www.internationalbudget.org/resources/library/civilsociety.pdf (May 29, 2008).

Lonsdale, J. (1986). Political accountability in African history. In P. Chabal (Ed.), Political Domination in Africa. Cambridge: Cambridge University Press, (Chapter 7).

Mainwaring, S. (2003). Introduction: democratic accountability in Latin America. In S. Mainwaring and C. Welna (Eds.), Democratic Accountability in Latin America. Oxford: Oxford University Press, (Chapter 1).

Mohamed Salih (Ed.) (2005) African Parliaments. Basingstoke: Macmillan Palgrave.

Moncrieffe, J. (2001). Accountability: idea, ideals, constraints. Democratization, 8:3, 26-50. 
O’Donnell, G. (1998). Horizontal accountability in new democracies. Journal of Democracy, 9:3, 112-26.

Posner, D. and Young, D. (2007). The institutionalization of political power in Africa. Journal of Democracy, 18:3, $126-40$.

Rackner, L. and Gloppen S. (2003). Tax reform and democratic accountability in sub-Saharan Africa. In N. van de Walle, N. Ball and V. Ramachandran (Eds.), Beyond Structural Adjustment: the Institutional Context of African Development. Basingstoke: Palgrave Macmillan, (Chapter 3).

Reynolds, A (Ed.) (2002). The Architecture of Democracy. Constitutional Design, Conflict Management and Democracy. Oxford: Oxford University Press.

Robinson, M. (2006) Budget analysis and policy advocacy: the role of nongovernmental public action Sussex: Institute of Development Studies Working Paper 279.

Schedler, A. (1999a). Introduction. In A. Schedler, L. Diamond and M. Plattner (Eds.), The Self-Restraining State: power and accountability in new democracies. Boulder, CO: Lynne Rienner, (Chapter 1).

Schedler, A. (1999b). Conceptualising accountability. In A. Schedler, L. Diamond and M. Plattner (Eds.), The Self-Restraining State: power and accountability in new democracies. Boulder, CO: Lynne Rienner, (Chapter 2).

Smulovitz, C. and Peruzotti, E. (2003). Societal and horizontal controls: two cases of a fruitful relationship. In S. Mainwaring and C. Welna (Eds.), Democratic Accountability in Latin America. Oxford: Oxford University Press, (Chapter 10).

Solnick, S. (2002). Federalism and state-building: post-communist and post-colonial. In A. Reynolds (Ed), The Architecture of Democracy.Constitutional Design, Conflict Management and Democracy. Oxford: Oxford University Press, (Chapter 7).

Sweet, A. Stone (2008). Constitutions and judicial power. In D. Carmani (Ed.), Comparative Politics. Oxford: Oxford University Press, (Chapter 9). 